\title{
Tanılar Üstü Psikolojik Müdahale Programlarının Depresyon ve Anksiyete Bozuklukları Üzerindeki Etkisi: Sistematik Bir Derleme
}

\section{Effect of Transdiagnostic Psychological Intervention Programs on Depression and Anxiety Disorders: A Systematic Review}

Özge Erarslan Ingeç' @, Orçun Yorulmaz' @

\section{öz}

Yaşam boyu birlikte görülme oranları oldukça yüksek olan depresyon ve anksiyete bozukluklarının etiyolojisindeki ortaklıklar birlikte ele alındığında, en son araştırmalar bu ortak özelliklerden hareketle geliştirilen bir dizi duygularla ilişkili bozukluğa uygulanabilen tanılar üstü bir yaklaşımı gündeme getirmiştir. Bu çalışmada tanılar üstü müdahale programlarının depresyon ve anksiyete bozuklukları üzerindeki etkilerini inceleyen görgül araştırmalar gözden geçirilmiştir. Yapılan incelemeler sonucunda ulaşılan 18 seçkisiz kontrollü ve 13 seçkisiz olmayan çalışma örneklem özellikleri, yöntemsel arka planları ve sonuçları bakımından incelenmiştir. Bu çalışma kapsamında incelenen araştırmalar genel olarak değerlendirildiğinde ilk olarak, tanılar üstü psikolojik müdahale programlarının çeşitli anksiyete bozuklukları ve depresyonun tedavisinde etkili olduğu sonucu çkarılabilir. Anksiyete ve depresif belirtilerin bir arada olduğu durumlarda tanılar üstü yaklaşımın tanıya özgü protokollere kıyasla önemli avantajlar sağlayabileceği önerilmektedir. Gelecek çalışmalarda bu yaklaşımın farklı tanı gruplarında tanıya özgü tedavilere kıyasla etkisinin incelenmesinin önemli olduğu sonucuna varılmıştır. Ülkemizde de tanılar üstü müdahalelerin etkinliğini ve tanıya özgü protokollere kıyasla olası klinik ve ekonomik avantajlarını araşııımanın önemli olduğu düşünülmektedir.

Anahtar sözcükler: Bilişsel davranış̧̧ terapi, bütünleşik protokol, duygularla ilişkili bozukluklar, depresyon, anksiyete bozuklukları, tanılar üstü

\section{Abstract}

By considering the etiological similarities of depression and anxiety disorders with high lifetime coexistence rates, recent research has introduced a transdiagnostic approach applicable to a range of emotional disorders with these common features. This paper reviews empirical studies examining the effects of transdiagnostic intervention programs on depression and anxiety disorders. The literature search identified 18 randomized controlled and 12 non-randomized studies. These were examined in terms of their sample characteristics, methodological approaches, and findings. Overall, the reviewed transdiagnostic psychological intervention programs treat various anxiety disorders and depression effectively. In cases where anxiety and depressive symptoms are comorbid, the transdiagnostic approach has significant advantages over diagnosis-specific protocols. Future studies should investigate the effect of the transdiagnostic approach in different diagnostic groups compared to diagnosis-specific treatments. In Turkey specifically, it is important to investigate the effectiveness of transdiagnostic interventions and potential clinical and economic advantages compared to diagnostic specific protocols.

Keywords: Cognitive behavioral therapy, unified protocol, emotional disorders, depression, anxiety disorders, transdiagnostic

'Dokuz Eylül Üniversitesi, İzmir, Türkiye

$凶$ Özge Erarslan İngeç, Dokuz Eylül Üniversitesi Edebiyat Fakültesi, Psikoloji Bölümü, İzmir, Türkiye ozgeerarslan89@gmail.com |0000-0001-5936-3066

Geliş tarihi/Received: 13.07.2020 | Kabul tarihi/Accepted: 23.09.2020 | Çevrimiçi yayı/Published online: 20.12.2020 
HERHANGİ bir psikolojik sorunu olanların neredeyse yarısının, geçmiş 12 aylık bir dönemde aynı anda birden fazla rahatsızlık ölçütünü karşıladığı rapor edilmektedir (Kessler ve ark. 2005); bu durum ise, psikolojik rahatsızlıklarda eş-tanının (komorbidite), pek çok açıdan önemli bir sorun olduğu düşüncesini pekiştirmektedir. En yaygin ruhsal bozukluklar arasında olan depresyon ve anksiyete bozukluklarının yaşam boyu tek başına görülme sıklı̆̆ı yaklaşık \%29 iken, bir arada görülme oranları \%40-80 arasında değişmektedir (Wittchen ve ark. 2011).

Günümüzde psikiyatrik rahatsızlıkları tanı ve sinıflandırmada kullanılan iki temel kaynak olan Ruhsal Bozuklukların Tanısal ve İstatistiksel El Kitabı (DSM; Diagnostic and Statistical Manual of Mental Disorders) ve ICD (The International Statistical Classification of Diseases and Related Health Problems) rahatsızlikları belirti kümeleri ile tanımlayarak kategorik olarak sınıflandırmışlardır. DSM-5'te (APA 2013) psikiyatrik rahatsızlıkları tanımlamaya ve sinıflandırmaya yönelik daha fazla durum ve belirleyiciler eklenerek tanı kategorileri birbirinden ayrıştırılmıştır. Her ne kadar mevcut tanı kategorileri orta ile neredeyse mükemmel güvenirlik göstermiş olsa da bu kategorilerin yararll1ıkları üzerine tartışmalar devam etmektedir (First ve ark. 2018). Bazı DSM rahatsılılklarının benzersiz yapıları temsil etmediğine aksine ortak bir sendromdaki varyasyonları yansıttığına dair artan kanitlar bulunmaktadır (Brown ve Barlow 2009).

Psikolojik rahatsızlıklarda görülen yüksek orandaki eş-tanı; depresyon ve anksiyete bozuklukların gelişimine katkı sağlayan ortak yatkınlıklar fikrini akla getirmektedir. İleri sürülen çeşitli ortak yatkınlık faktörleri arasında anksiyete, depresyon ve ilişkili bozukluklara sahip bireylerin sağlıklı kişilere kıyasla daha yüksek düzeyde olumsuz duygulanıma sahip olmaları (Mennin ve ark. 2005), duygusal deneyimlerini daha olumsuz bir şekilde yorumlama eğilimi göstermeleri (Roemer ve ark. 2005), duyguların olumsuz etkilerini azaltmayı amaçlayan bir dizi işlevsel olmayan bilişsel ve davranı̧sal strateji sergilemeleri başta gelmektedir (Barlow 2004). Bu ortaklıkların en dikkat çekici açılaması ise, bu örüntünün "genel nevrotik sendrom" olarak adlandırılabilecek ortak bir arka planı olması iddiasıdır. Bu iddiaya göre farklı rahatsılıklarda görülen benzer belirtiler, daha üst bir sendromun ortaya çıkı̧ındaki ufak farklılıklardan kaynaklanabilir. Tüm bu ortaklıklar öne sürülerek anksiyete, depresyon, somatoform ve hatta disosiyatif bozukluklar gibi ilişkili bozuklukları gruplamak için de "duygularla ilişkili bozukluklar (emotional disorders)" terimi ileri sürülmüştür (Brown ve Barlow 2009).

Yüksek komorbidite oranı, tedavi sonucunda ortaya çıkan sonuçlarda benzerlikler ve duygularla ilişkili bozuklukların kökenindeki ortaklıklar bir dizi soruna uygulanabilen tanılar üstü bir müdahale yaklaşımını gündeme getirmiştir. Birçok soruna ortak tedavi ilkelerini uygulamak amacıyla bazı "geniş spektrumlu" tedavi protokolleri tasarlanmaya başlanmıştır; diğer deyişle, bu protokollerin spesifik olarak sadece anksiyete ve depresif bozukluklara değil aynı zamanda eşlik eden diğer pek çok soruna da uygulanması hedeflenmektedir (Norton ve ark. 2013).

Tanılar üstü tedavi protokolleri genellikle iki ana yaklaşımla ele alınmaktadır (Craske 2012). İlki, çeşitli psikolojik bozukluklarının sürdürülmesinde rol oynadığı öne sürülen 
belli bir tanılar üstü faktöre (duygu düzenleme güçlüğü, ruminasyon ve uyum bozucu mükemmeliyetçilik) yönelik uygulanan kabul temelli stratejilere karşılık gelmektedir (Twohig ve ark. 2010). Bu gözden geçirme çalışmasının odağı olan ikinci yaklaşım ise geleneksel Bilişsel Davranış̧ı Terapi (BDT) stratejilerinin belli bir tanı kategorisinde yer alan çeşitli bozukluklara genel bir şekilde uygulanmasını içermektedir (Norton 2012). Bu yaklaşım geleneksel BDT'den temel olarak ortak altta yatan mekanizmalara ve bu mekanizmaları değiştirmek için yararlanılan stratejilerin genel kullanımına odaklanması açısından farklılaşmaktadır. Öte yandan, tanılar üstü yaklaşımların tedavi bileşenleri arasında davranışsal ya da yaşantısal kaçınma, bilişsel yeniden yapılandırma, bilinçli farkındalık veya duygu düzenleme stratejilerinin yer aldığ1 söylenebilir. Bireysel ya da grup terapisi formunda ya da internet aracılığıyla uygulanan tanılar üstü tedavilerin bilimsel çalışmalar ile etkinliği gösterilmiş; bu bulgular ayrıca tedavi protokolü geliştirenlerden bağımsız araştırma ekipleri tarafından tekrarlanmıştır (Sakiris ve Berle 2019). Hatta internet üzerinden uygulanan versiyonlarının da olumlu sonuçlar ürettiğinden söz etmek mümkündür (örn. Titov ve ark. 2011).

Tanılar üstü protokollerin içerik, biçim ve tedavi vurgularına genel bir bakış sağlamak için bu çalışma kapsamında dahil edilen ve alanyazında en dikkat çeken iki müdahale programına kısaca değinilecektir (Meidlinger ve Hope 2017). Tarihsel açıdan da ilk çıkan ve daha popüler olan program Barlow ve ekibinin (2011) geliştirdiği Duygularla İlişkili Bozuklulara Yönelik Bütünleşik Protokol'dür (Unified Protocol for Emotional Disorders). Bu protokol, tanılara özgü müdahale programlarının gerçek dünya koşullarını tam karşılamadığı ve klinisyenleri zorda bıraktığ1 eleştirilerinden ortaya çıkan tanılar üstü yaklaşıma dayalı bir protokoldür. Protokolün amacı, danışanların duygularını anlamalarına ve tanımalarına ve rahatsız edici olumsuz duygularına daha uyumlu şekilde yanıt vermelerine yardımcı olmaktır. Böylesi bir yaklaşımın, rahatsız edici duyguların yoğunluğunu ve sıklığını azaltabileceği ve yaşam kalitesini artırabileceği varsayılmıştır. Haftada bir, her biri yaklaşık bir saat süren toplamda 12-18 seans arasında değişen protokol, 5 temel tedavi modülü ve 3 ek modülden oluşmaktadır. Her modülün oturum sayısının, danışanın gelişimine bağlı olarak esneklik gösterebilmesi önemli bir avantajdır. Beş temel tedavi modülü, duygularla ilişkili bozukluklardaki işlevsel ilişkileri yansıtan tanılar üstü yapılara karşılık gelmektedir; bunlar duygu farkındalığı, bilişsel yeniden yapılandırma, duygu kaynaklı davranışlar ve duygusal kaçınma, fiziksel duyumların farkındalığı ve toleransı, içsel (interoceptive) ve durumsal maruz bırakma şeklinde sıralanabilir. Tanılar üstü yaklaşımı benimseyen diğer bir protokol olan Tanılar Üstü Bilişsel Davranışçı Grup Terapisi (Transdiagnostic Cognitive Behavioral Group Treament) Norton ve ekibi tarafından anksiyete bozukluklarına yönelik geliştirilmiştir (Norton 2012). Her biri 2 saat süren 12 seanstan oluşan bu tanılar üstü grup tedavisinin ilk 9 seansında, BDT’nin üç temel bileşenine odaklanılır: psikoeğitim ve kendi kendini izleme, bilişsel yeniden yapılandırma ve korkulan uyaranlara maruz kalma. Daha sonra terapi odağı1, mevcut sıkıntıların ötesinde altta yatan kontrol edilemezlik, öngörülemezlik ve tehdit algılarına doğru kaydırılmaktadır. Tedavinin ilk aşamasında da öne çıkan bilişsel 
yeniden yapılanma bu aşamada, acil ve en belirgin korkulara değil, günlük yaşamın genel sıkıntı üreten yönlerine uygulanmaktadır.

Birçok psikolojik rahatsızlıkların altında yatan nedenleri ve sürdürücü ortak faktörleri hedefleyen tanılar üstü tedavi yaklaşımları umut verici sonuçlar ortaya çıkarmıştır (Newby ve ark. 2015). Araştırma bulguları 1şığında, bu derleme çalışmasının amacı Bütünleşik Protokol, Tanılar Üstü Bilişsel Davranış̧̧ı Grup Terapisi ve internet destekli tanılar üstü bilişseldavranış̧ı terapi protokollerinin depresyon ve anksiyete bozuklukları üzerindeki etkisine ilişkin görgül çalışmaları içeren sistematik bir derleme yapmaktır. Bu amaç doğrultusunda, araştırmaları mevcut seçkisiz kontrollü çalışmalarla (SKÇ) sınırlamanın ötesinde daha kapsayıcı olmak için seçkisizlik içermese de ön test-son test çalışma desenine sahip yani kontrollü çalışmalar (KÇ) da dahil edilmiştir. Mevcut gözden geçirme çalışmalarından farklı olarak tanılar üstü müdahalelerin bireysel ve grup temelli uygulamalarına ek olarak yaygınlığı gittikçe artan internet destekli uygulamalarına da yer verilmiştir. Ulusal Akademik A ğ ve Bilgi Merkezi (Ulakbim) ve TR dizin veri tabanlarında "tanılar üstü", "transdiagnostik", "bütünleşik protokol” anahtar kelimeleri ile yapılan taramada herhangi bir psikolojik müdahale çalışmasına rastlanmamıştır. Psikolojik rahatsızlıkların tedavisinin yaygınlaştırılmasında ve ulaşılabilir olmasında önemli olabileceği düşünülen tanılar üstü yaklaşımın incelenmesinin alana özgün katkı sağlaması beklenmektedir.

\section{Yöntem}

$\mathrm{Bu}$ çalı̧̧mada özellikle anksiyete ve depresif bozukluklarda tanılar üstü protokollerin hangi amaçlarla kullanıldığına, hangi psikolojik değişkenlere dair ölçümlerin alındığına, örnekleme dair özelliklere ve araştırma sonuçlarına odaklanılmıştır. Bu amaçla Web of Science, PubMed, SAGE Journals ve Science Direct veri tabanları "unified protocol", "transdiagnostic", "depression", "anxiety disorders"ve "emotional disorders" anahtar kelimeleri ile taranmıştır. Alanyazın incelenirken tanılar üstü protokoller görece yeni bir uygulama olduğu için herhangi bir zaman kısıtlamasına gidilmemiştir. Yapılan taramada bahsi geçen 4 veri tabanında toplam 684 çalışmaya ulaş1mıştır (PubMed= 222, Web of Science= 126, SAGE Journals= 97, Science Direct= 239). Veri tabanlarında tekrarlayan çalışmaların çıkarılması ile kalan 380 çalışmanın başlık ve özet kısımları incelenmiş, ilişkisiz çalışmalar $(n=105)$ çıkarıldıktan sonra dahil etme-çıkarma ölçütleri doğrultusunda nihai veri setine karar verilmiştir. Çıkarma ölçütleri arasında gözden geçirme ve meta-analiz çalışmaları ( $\mathrm{n}=158)$, BDT yaklaşımı dışında bilinçli farkındalık ve psikodinamik gibi farklı temelleri olan müdahaleleri içeren çalışmalar ( $\mathrm{n}=13), 18$ yaş altını kapsayan örneklem grupları ile yürütülen çalı̧̧malar ( $n=36)$, vaka sunumları $(n=9)$, kısa süreli psikoterapilerin kullanılması $(n=3)$, istatistiksel analizlerin sunulmaması $(n=5)$, nitel çalışma $(n=1)$, tedavi odağı depresyon ve anksiyete bozuklukları olmayan örneklem grupları $(n=9$, kişilik bozuklukları, yeme bozukluğu) ve İngilizce yayınlanmayan çalışmalar ( $n=3)$ sayılabilir. Ayrıca heterojenliği azaltmak için tanılar üstü müdahale programlarının depresif ve anksiyete bozukluklarındaki etkisine odaklanılmış; alanyazında görece yeni tarihli olan ve savaş gazilerinde görülen özellikle Travma Sonrası Stres Bozukluğu belirtilerine yönelik geliştirilmiş müdahaleler 
olay odaklı ve belli bir duruma özgü olması nedeniyle bu çalışmaya dahil edilmemiştir ( $n=5$; the Common Elements Treatment Approach ve Transdiagnostic Behavioral Therapy). Son olarak, koşullardan ötürü günümüzde kullanımı giderek yaygınlaşan müdahalelerde teknoloji kullanımı da hesaba katılarak alanyazında ve uygulamada internet destekli psikolojik müdahale programlarını içeren görgül çalışmalar da bu derlemeye dahil edilmiştir. Yine de bu tür programların içeriği gereği belirli ölçüde terapist varlı̆̆ 1 gerektiği için bu tür yayınlarda terapist etkileşimi bir dahil edilme kriteri olarak alınmış ve terapistin herhangi bir şekilde yer almadığı veya sadece e-postalarla yürütülen çalışmalar dahil edilmemiştir $(n=2)$.

Sonuç olarak, söz edilen dahil edilme ölçütlerini sağlamayan 244 çalışma da çıkarıldığında, müdahalenin etkisini değerlendirmek amacıyla geriye 18 seçkisiz kontrollü çalışma (SKÇ) ve 13 seçkisiz olmayan kontrollü çalışma (KÇ) kalmıştır. Bu noktada bu derleme için yapılan taramada, önemli bir konu olan anksiyete ve depresif bozukluklarla ilgili ek bir açıklamaya yer vermek doğru olacaktır: her ne kadar son yillarda bozukluklara dair sınıflandırmalarda birtakım değişiklikler olsa da çalışmanın daha kapsayıcı olması için önceki sınıflandırma temel alınmıştır. Diğer deyişle, burada bahsedilecek araştırmalarda tek uçlu duygu durum bozuklukları olarak ifade edildiğinde majör depresif bozukluk, distimik bozukluk ve başka türlü tanımlanmayan depresyon kastedilirken, anksiyete bozuklukları olarak ifade edildiğinde ise yaygin anksiyete bozukluğu, agorafobiyle birlikte görülen ya da agorafobisiz panik bozukluk, sosyal fobi, travma sonrası stres bozukluğu, obsesif-kompulsif bozukluk, spesifik fobi ve başka türlü tanımlanmayan anksiyete bozukluğundan söz edilmektedir. Takip eden bölümde dahil edilen çalışmalardan detaylı bir şekilde bahsedilecek olup, çalışmaların genel özellikleri ve araştırma bulgularının yer aldığı özet bilgiler Tablo 1'de sunulmuştur.

\section{Bulgular}

\section{Bireysel olarak uygulanan protokoller}

Derleme sonucunda ulaşılan görgül çalışmaların bir kısmının bireysel olarak uygulanan Barlow ve ekibi tarafından geliştirilen Bütünleşik Protokol'ün tek başına depresyon ve anksiyete bozuklukları üzerindeki etkisini inceledikleri, diğer bir kısmının ise eş tanı olarak görülen depresyon ve anksiyete bozuklukları üzerindeki etkisine odaklandıkları görülmüştür. Bu sebeple, bu kısımda öncelikle bu iki grup çalışmanın sonuçları verilecektir

\section{Depresyon ve anksiyete bozuklukları üzerindeki etkisi}

Duygularla ilişkili bozuklukların tanılar üstü tedavisi için Bütünleşik Protokol'ün etkinliğinin değerlendirilmesi üzerine ilk çalışma 2012 yılında yapılmış olup, birincil tanısı anksiyete bozukluğu olan 37 katılımcı seçkisiz bir şekilde tedavi grubuna ya da bekleme listesi kontrol grubuna atanmıştır (Farchione ve ark. 2012). Bütünleşik Protokol alan grupta klinik şiddet, depresyon ve anksiyetenin genel belirtileri, olumlu ve olumsuz duygu düzeyleri ve günlük işlevsellik ölçümlerinde, hem ön test puanlarına hem de kontrol grubuna kıyasla anlamlı iyileşme ile sonuçlandığ1 görülmüştür. Çalışmada müdahalenin etkilerinin 6 aylık takip 
Tablo 1. Kapsanan araştırmaların genel özellikleri

\begin{tabular}{|c|c|c|c|c|c|c|}
\hline Çalışma & $\begin{array}{l}\text { Çalışma } \\
\text { özelliği }\end{array}$ & Kapsanan bozukluk & $\begin{array}{l}\text { Kontrol } \\
\text { grubu }\end{array}$ & $\begin{array}{l}\text { Katılımc } \\
\text { sayısı }\end{array}$ & İzlem & Temel bulgular \\
\hline $\begin{array}{l}\text { Farchione ve } \\
\text { ark. } 2012\end{array}$ & $\begin{array}{l}\text { SKÇ, } \\
\text { bireysel }\end{array}$ & $\begin{array}{l}\text { YAB, sosyal fobi, panik } \\
\text { bozukluk, OKB ve TSSB }\end{array}$ & Var & 37 & 6 ay & $\begin{array}{l}\text { Bütünleşik Protokol alan grupta } \\
\text { kontrol grubuna kıyasla anksiyete } \\
\text { belirtilerinde anlamlı iyileşme } \\
\text { görülmüşsür. }\end{array}$ \\
\hline $\begin{array}{l}\text { Bullis ve ark. } \\
2014\end{array}$ & $\begin{array}{l}\text { Ön test-son } \\
\text { test }\end{array}$ & $\begin{array}{l}\text { YAB, sosyal fobi, panik } \\
\text { bozukluk ve OKB }\end{array}$ & - & 15 & 12 ay & $\begin{array}{l}\text { Bütünleşik Protokol alan } \\
\text { katııımcıların tedavi kazanımlarının } \\
12 \text { aylık takip ölçümü sonuçlarında } \\
\text { anlamlı şekilde sürdürüldüğü rapor } \\
\text { edilmiştir. }\end{array}$ \\
\hline $\begin{array}{l}\text { Barlow ve ark. } \\
2017\end{array}$ & $\begin{array}{l}\text { SKÇ, } \\
\text { bireysel }\end{array}$ & $\begin{array}{l}\text { YAB, agorafobiyle } \\
\text { birlikte görülen ya da } \\
\text { agorafobisiz panik } \\
\text { bozukluk, sosyal fobi } \\
\text { ve OKB }\end{array}$ & Var & 223 & 6 ay & $\begin{array}{l}\text { Bütünleşik Protokol ve standart } \\
\text { protokoller arasında istatiksel olarak } \\
\text { anlamlı bir fark bulunmamıştır. }\end{array}$ \\
\hline $\begin{array}{l}\text { Khakpoor ve } \\
\text { ark. } 2019\end{array}$ & $\begin{array}{l}\text { SKÇ, } \\
\text { bireysel }\end{array}$ & $\begin{array}{l}\text { YAB, sosyal fobi, panik } \\
\text { bozukluk, OKB ve } \\
\text { depresyon }\end{array}$ & Var & 26 & - & $\begin{array}{l}\text { Müdahale grubunda olan kişilerin } \\
\text { kontrol grubundakilere kıyasla } \\
\text { anksiyete ve depresif belirtilerinde } \\
\text { azalma gözlenmiştir. }\end{array}$ \\
\hline $\begin{array}{l}\text { Mohajerin ve } \\
\text { ark. } 2019\end{array}$ & $\begin{array}{l}\text { SKÇ, } \\
\text { bireysel }\end{array}$ & $\begin{array}{l}\text { Beden dismorfik } \\
\text { bozukluğu }\end{array}$ & Var & 128 & 3 ay & $\begin{array}{l}\text { Bütünleşik Protokol'ün kontrol } \\
\text { grubuna kıyasla depresyon, } \\
\text { dismorfik bozukluğu belirtilerini ve } \\
\text { bedenle ilişkili anksiyeteyi anlamlı } \\
\text { şekilde azalttığı bulunmuştur. }\end{array}$ \\
\hline $\begin{array}{l}\text { Ellard ve ark. } \\
2017\end{array}$ & $\begin{array}{l}\text { SKÇ, } \\
\text { bireysel }\end{array}$ & Bipolar bozukluk & Var & 29 & - & $\begin{array}{l}\text { Müdahale grubunda olan } \\
\text { katılımcıların zaman içinde } \\
\text { anksiyete ve depresif belirtilerinde } \\
\text { anlamlı bir şekilde daha fazla } \\
\text { azalma rapor edilmiştir. }\end{array}$ \\
\hline $\begin{array}{l}\text { Bentley ve ark. } \\
2017\end{array}$ & $\begin{array}{l}\text { SKÇ, } \\
\text { bireysel }\end{array}$ & $\begin{array}{l}\text { İntihar girişimi ya da } \\
\text { intihar düşüncesi }\end{array}$ & Var & 12 & 6 ay & $\begin{array}{l}\text { Her zamanki tedaviye Bütünleşik } \\
\text { Protokol'ün eklenmesinin } \\
\text { uygulanabilir ve kabul edilebilir } \\
\text { olduğu desteklenmiştir. }\end{array}$ \\
\hline $\begin{array}{l}\text { Ciraulo ve ark. } \\
2013\end{array}$ & $\begin{array}{l}\text { SKÇ, } \\
\text { bireysel }\end{array}$ & $\begin{array}{l}\text { Alkol kullanım } \\
\text { bozukluğu + panik } \\
\text { bozukluğu, sosyal fobi } \\
\text { ve YAB }\end{array}$ & Var & 81 & $\begin{array}{l}3,6,9 \text { ve } \\
12 \text { ay }\end{array}$ & $\begin{array}{l}\text { Placebo + Bütünleşik Protokol } \\
\text { grubundaki katılımcıların günlük } \\
\text { alkollü içki içme yüzdesi kontrol } \\
\text { grubuna kıyasla anlamlı bir düşüş } \\
\text { göstermiştir. }\end{array}$ \\
\hline $\begin{array}{l}\text { Vand ve ark. } \\
2018\end{array}$ & $\begin{array}{l}\text { Ön test-son } \\
\text { test, } \\
\text { bireysel }\end{array}$ & $\begin{array}{l}\text { Uykusuzluk + } \\
\text { depresyon, YAB, OKB, } \\
\text { panik bozukluk ve } \\
\text { sosyal fobi }\end{array}$ & - & 6 & 3 ay & $\begin{array}{l}\text { Katılımcıların tedavi öncesine } \\
\text { kıyasla, tedavi sonunda alınan } \\
\text { sonuç ölçümlerinde anlamlı } \\
\text { iyileşme gözlemiştir. }\end{array}$ \\
\hline $\begin{array}{l}\text { Mohsenabadi } \\
\text { ve ark. } 2018\end{array}$ & $\begin{array}{l}\text { SKÇ, } \\
\text { bireysel }\end{array}$ & $\begin{array}{l}\text { IBS+ depresyon veya } \\
\text { anksiyete belirtileri }\end{array}$ & Var & 64 & - & $\begin{array}{l}\text { Müdahale sonrası katıımcıların } \\
\text { hem depresyon, anksiyete, stres ve } \\
\text { gastrointestinal belirtilerinde hem } \\
\text { de duygu düzenleme puanlarında } \\
\text { anlamlı iyileşmeler olduğu rapor } \\
\text { edilmiştir. }\end{array}$ \\
\hline
\end{tabular}


Tablo 1. Devamı

\begin{tabular}{|c|c|c|c|c|c|c|}
\hline Çalışma & $\begin{array}{l}\text { Çalışma } \\
\text { özelliği }\end{array}$ & Kapsanan bozukluk & $\begin{array}{l}\text { Kontrol } \\
\text { grubu }\end{array}$ & $\begin{array}{l}\text { Katılımc } \\
\text { sayısı }\end{array}$ & İzlem & Temel bulgular \\
\hline $\begin{array}{l}\text { Weihs ve ark. } \\
2019\end{array}$ & $\begin{array}{l}\text { Ön test-son } \\
\text { test, } \\
\text { bireysel }\end{array}$ & $\begin{array}{l}\text { Meme kanseri + } \\
\text { depresyon }\end{array}$ & - & 15 & - & $\begin{array}{l}\text { Bütünleşik Protokol'ün yakın } \\
\text { zamanda meme kanseri teşhisi } \\
\text { alan bireylerde depresyonu } \\
\text { önleyebileceği desteklenmiştir. }\end{array}$ \\
\hline $\begin{array}{l}\text { Norton ve Hope } \\
2005\end{array}$ & SKÇ, grup & $\begin{array}{l}\text { YAB, OKB, sosyal } \\
\text { fobi ve agorafobiyle } \\
\text { birlikte görülen ya da } \\
\text { agorafobisiz panik } \\
\text { bozukluk }\end{array}$ & Var & 23 & - & $\begin{array}{l}\text { Müdahale grubunda yer alan } \\
\text { katılımcılarda tanıya yönelik } \\
\text { ölçümlerinde ve korku-kaçınma } \\
\text { hiyerarşilerinde daha fazla iyileşme } \\
\text { gözlenmiştir. }\end{array}$ \\
\hline Norton 2008 & $\begin{array}{l}\text { Ön test-son } \\
\text { test, grup }\end{array}$ & $\begin{array}{l}\text { Anksiyete bozuklukları } \\
\text { (çoğunlukla panik } \\
\text { bozukluk ve sosyal fobi) }\end{array}$ & - & 52 & - & $\begin{array}{l}\text { Katılımcıların tedavi boyunca } \\
\text { iyileşme eğiliminde oldukları } \\
\text { bulunmuştur. }\end{array}$ \\
\hline Norton 2012 & SKÇ, grup & $\begin{array}{l}\text { YAB, sosyal fobi, özgül } \\
\text { fobi ve BTA anksiyete } \\
\text { bozukluğu }\end{array}$ & Var & 87 & - & $\begin{array}{l}\text { Gruplara atanan katılımcıların } \\
\text { tedavi sonuçları arasında anlamlı } \\
\text { farklılık bulunmamakla birlikte, } \\
\text { gevşeme grubunda tedaviyi yarıda } \\
\text { bırakma oranlarının daha yüksek } \\
\text { olduğu belirtilmiştir. }\end{array}$ \\
\hline $\begin{array}{l}\text { Norton ve } \\
\text { Barrera } 2012\end{array}$ & SKÇ, grup & $\begin{array}{l}\text { Panik bozukluk, sosyal } \\
\text { fobi ve YAB }\end{array}$ & Var & 46 & - & $\begin{array}{l}\text { Bozukluklara özgü BDT grup } \\
\text { terapisi ile tanılar üstü grup terapisi } \\
\text { karşılaştırıldığında her iki grupta yer } \\
\text { alan katılımcıların tedavi boyunca } \\
\text { anlamlı iyileşmeler gösterdikleri } \\
\text { ve müdahalelerin etkinliklerinde } \\
\text { farklılık olmadığı bulunmuştur. }\end{array}$ \\
\hline $\begin{array}{l}\text { Bullis ve ark. } \\
2015\end{array}$ & $\begin{array}{l}\text { Ön test-son } \\
\text { test, grup }\end{array}$ & $\begin{array}{l}\text { Depresyon ve/veya } \\
\text { sosyal fobi, agorafobiyle } \\
\text { birlikte görülen ya da } \\
\text { agorafobisiz panik } \\
\text { bozukluk, YAB, OKB } \\
\text { ve BTA anksiyete } \\
\text { bozukluğu }\end{array}$ & - & 11 & - & $\begin{array}{l}\text { Bütünleşik protokolün anksiyete ve } \\
\text { depresif belirtiler, işlevsel bozukluk, } \\
\text { yaşam kalitesi ve duygu düzenleme } \\
\text { becerileri üzerinde iyi düzeyde } \\
\text { etkiye sahip olduğu rapor edilmiştir. }\end{array}$ \\
\hline $\begin{array}{l}\text { Reinholt ve ark. } \\
2017\end{array}$ & $\begin{array}{l}\text { Ön test-son } \\
\text { test, grup }\end{array}$ & $\begin{array}{l}\text { Agorafobiyle birlikte } \\
\text { görülen panik bozukluk, } \\
\text { sosyal fobi ve YAB }\end{array}$ & - & 47 & - & $\begin{array}{l}\text { Semptom şiddeti, anksiyete ve } \\
\text { psikolojik iyi oluş düzeylerinde } \\
\text { klinik olarak anlamlı değişimler } \\
\text { rapor edilmiştir. }\end{array}$ \\
\hline $\begin{array}{l}\text { De Ornelas Maia } \\
\text { ve ark. } 2015\end{array}$ & $\begin{array}{l}\text { Ön test-son } \\
\text { test, grup }\end{array}$ & $\begin{array}{l}\text { Depresyon, YAB, panik } \\
\text { bozukluk, TSSB ve } \\
\text { sosyal fobi }\end{array}$ & Var & 48 & - & $\begin{array}{l}\text { İlaç tedavisine kıyasla Bütünleşik } \\
\text { Protokol'ün depresif ve anksiyete } \\
\text { belirtilerinin iyileşmesinde oldukça } \\
\text { etkili olduğu rapor edilmiştir. }\end{array}$ \\
\hline $\begin{array}{l}\text { Mohammadi ve } \\
\text { ark. } 2013\end{array}$ & SKÇ, grup & $\begin{array}{l}\text { Depresyon ve anksiyete } \\
\text { belirtileri }\end{array}$ & Var & 33 & - & $\begin{array}{l}\text { Bütünleşik Protokol ve standart } \\
\text { BDT karşılaştırılmasında anksiyete } \\
\text { haricinde diğer tüm değişkenlerde } \\
\text { anlamlı farklılık olmadığı rapor } \\
\text { edilmiş̧ir. Tanılar üstü grup terapisi } \\
\text { anksiyete belirtilerinin azalmasında } \\
\text { anlamlı bir farklılık sergilemiştir. }\end{array}$ \\
\hline
\end{tabular}


Tablo 1. Devamı

\begin{tabular}{|c|c|c|c|c|c|c|}
\hline Çalışma & $\begin{array}{l}\text { Çalışma } \\
\text { özelliği }\end{array}$ & Kapsanan bozukluk & $\begin{array}{l}\text { Kontrol } \\
\text { grubu }\end{array}$ & $\begin{array}{l}\text { Katılımc } \\
\text { sayısı }\end{array}$ & İzlem & Temel bulgular \\
\hline $\begin{array}{l}\text { De Ornelas Maia } \\
\text { ve ark. } 2017\end{array}$ & SKÇ, grup & $\begin{array}{l}\text { Cinsel işlev bozukluğu } \\
+ \text { depresif ve anksiyete } \\
\text { belirtileri }\end{array}$ & Var & 48 & - & $\begin{array}{l}\text { Bütünleşik müdahale alan grupta } \\
\text { cinsel işlev, yaşam kalitesi, } \\
\text { anksiyete ve depresyon belirtilerinin } \\
\text { tümünde anlamlı bir şekilde } \\
\text { iyileşme rapor edilmiştir }\end{array}$ \\
\hline $\begin{array}{l}\text { Tulbure ve ark. } \\
2018\end{array}$ & $\begin{array}{l}\text { SKÇ, } \\
\text { internet } \\
\text { destekli }\end{array}$ & $\begin{array}{l}\text { Depresif ve anksiyete } \\
\text { belirtileri }\end{array}$ & Var & 105 & - & $\begin{array}{l}\text { Kontrol grubuna kıyasla, tanılar } \\
\text { üstü müdahalenin anksiyete } \\
\text { ve depresif belirtilerin yanı sıra } \\
\text { anksiyete duyarlılığı ve yaşam } \\
\text { kalitesi üzerinde de olumlu etki } \\
\text { gösterdiği rapor edilmiştir. }\end{array}$ \\
\hline $\begin{array}{l}\text { Titov ve ark. } \\
2010\end{array}$ & $\begin{array}{l}\text { SKÇ, } \\
\text { internet } \\
\text { destekli }\end{array}$ & $\begin{array}{l}\text { YAB, panik bozukluk ve } \\
\text { sosyal fobi }\end{array}$ & Var & 86 & 3 ay & $\begin{array}{l}\text { Kontrol grubuna kıyasla, tedavi } \\
\text { grubundaki katıımcıların anksiyete } \\
\text { belirtilerinde anlamlı bir şekilde } \\
\text { azalma gözlenmiştir. }\end{array}$ \\
\hline $\begin{array}{l}\text { Titov ve ark. } \\
2011\end{array}$ & $\begin{array}{l}\text { SKÇ, } \\
\text { internet } \\
\text { destekli }\end{array}$ & $\begin{array}{l}\text { Depresyon, YAB, panik } \\
\text { bozukluk ve sosyal fobi }\end{array}$ & Var & 77 & 3 ay & $\begin{array}{l}\text { Kontrol grubuna kıyasla, müdahale } \\
\text { grubundaki katııımcıların anksiyete } \\
\text { ve depresyon belirtilerinde anlamlı } \\
\text { bir şekilde azalma olduğu rapor } \\
\text { edilmiş̧tir. }\end{array}$ \\
\hline $\begin{array}{l}\text { Dear ve ark. } \\
2011\end{array}$ & $\begin{array}{l}\text { Ön test-son } \\
\text { test, } \\
\text { internet } \\
\text { destekli }\end{array}$ & $\begin{array}{l}\text { Depresyon, YAB, panik } \\
\text { bozukluk ve sosyal fobi }\end{array}$ & - & 32 & 3 ay & $\begin{array}{l}\text { Katılımcıların depresif ve anksiyete } \\
\text { belirtilerinde anlamlı bir şekilde } \\
\text { iyileşme gözlenmiştir }\end{array}$ \\
\hline $\begin{array}{l}\text { Mullin ve ark. } \\
2015\end{array}$ & $\begin{array}{l}\text { SKÇ, } \\
\text { internet } \\
\text { destekli }\end{array}$ & $\begin{array}{l}\text { Depresif ve anksiyete } \\
\text { belirtileri }\end{array}$ & Var & 55 & 3 ay & $\begin{array}{l}\text { Kontrol grubuna kıyasla müdahale } \\
\text { alan grubun anksiyete ve depresif } \\
\text { belirtilerinde anlamlı iyileşmeler } \\
\text { tespit edilmiştir. }\end{array}$ \\
\hline $\begin{array}{l}\text { Newby ve ark. } \\
2017\end{array}$ & $\begin{array}{l}\text { Ön test-son } \\
\text { test, } \\
\text { internet } \\
\text { destekli }\end{array}$ & YAB ve depresyon & Var & 1005 & - & $\begin{array}{l}\text { Bütünleşik protokol ve tanıya özgü } \\
\text { müdahale depresyon ve yaygın } \\
\text { anksiyete bozukluğu için benzer } \\
\text { düzeyde etki göstermiştir. }\end{array}$ \\
\hline $\begin{array}{l}\text { Johnston ve ark. } \\
2011\end{array}$ & $\begin{array}{l}\text { SKÇ, } \\
\text { internet } \\
\text { destekli }\end{array}$ & $\begin{array}{l}\text { YAB, sosyal fobi } \\
\text { ve agorafobiyle } \\
\text { birlikte görülen ya da } \\
\text { agorafobisiz panik } \\
\text { bozukluk }\end{array}$ & Var & 129 & 3 & $\begin{array}{l}\text { Terapistin ve eğitmenin destek } \\
\text { verdiği gruplardaki katılımcıların } \\
\text { anksiyete ve depresif ölçümlerinde } \\
\text { kontrol grubundakilere kıyasla daha } \\
\text { iyi sonuçlar görülse de terapist } \\
\text { destekli grupta sonuçlar takip } \\
\text { ölçümleri de dahil olmak üzere } \\
\text { daha iyidir. }\end{array}$ \\
\hline $\begin{array}{l}\text { Johnston ve ark. } \\
2013\end{array}$ & $\begin{array}{l}\text { Ön test-son } \\
\text { test, } \\
\text { internet } \\
\text { destekli }\end{array}$ & $\begin{array}{l}\text { YAB, sosyal fobi } \\
\text { ve agorafobiyle } \\
\text { birlikte görülen ya da } \\
\text { agorafobisiz panik } \\
\text { bozukluk }\end{array}$ & Var & 129 & 3 & $\begin{array}{l}\text { Eş tanısı olan katılımcılar tedavi } \\
\text { öncesi, sonrası ve takip sürecinde } \\
\text { daha yüksek belirti rapor etse de } \\
\text { müdahale programı sonrasında eş } \\
\text { tanılı katılımcıların sorunlarında } \\
\text { azalmanın daha belirgin olduğu } \\
\text { bulunmuştur. }\end{array}$ \\
\hline
\end{tabular}


Tablo 1. Devamı

\begin{tabular}{|c|c|c|c|c|c|c|}
\hline Çalışma & $\begin{array}{l}\text { Çalışma } \\
\text { özelliği }\end{array}$ & Kapsanan bozukluk & $\begin{array}{l}\text { Kontrol } \\
\text { grubu }\end{array}$ & $\begin{array}{l}\text { Katılımc } \\
\text { sayısı }\end{array}$ & İzlem & Temel bulgular \\
\hline $\begin{array}{l}\text { Hadjistavropoulos } \\
\text { ve ark. } 2016\end{array}$ & $\begin{array}{l}\text { Ön test-son } \\
\text { test, } \\
\text { internet } \\
\text { destekli }\end{array}$ & $\begin{array}{l}\text { Depresif ve anksiyete } \\
\text { belirtileri }\end{array}$ & Var & 458 & - & $\begin{array}{l}\text { Ruh sağlığı veya genel sağlık } \\
\text { çalışanı eşliğinde yürütülen } \\
\text { gruplar arasında anlamlı bir fark } \\
\text { olmadığı belirtilmiş̧ir. }\end{array}$ \\
\hline $\begin{array}{l}\text { Owens ve ark. } \\
2018\end{array}$ & $\begin{array}{l}\text { Ön test-son } \\
\text { test, } \\
\text { internet } \\
\text { destekli }\end{array}$ & Sağlık anksiyetesi & - & 72 & 3 ay & $\begin{array}{l}\text { Tedavi sonrası sağlık anksiyetesi, } \\
\text { depresyon, yaygın anksiyete } \\
\text { belirtilerinde anlamlı azalmalar } \\
\text { olduğu rapor edilmiştir }\end{array}$ \\
\hline Dear ve ark. 2018 & $\begin{array}{l}\text { Ön test-son } \\
\text { test, } \\
\text { internet } \\
\text { destekli }\end{array}$ & $\begin{array}{l}\text { Sindirim sistemi } \\
\text { rahatsızlıkları }\end{array}$ & - & 27 & 3 ay & $\begin{array}{l}\text { Katılımcıların sindirim sistemi } \\
\text { şikayetleri ile anksiyete ve } \\
\text { depresyon belirtilerinde anlamlı } \\
\text { iyileşmeler gözlenmiştir. }\end{array}$ \\
\hline
\end{tabular}

SKÇ: Seçkisiz kontrollü çalışma, YAB: Yaygın anksiyete bozukluğu, OKB: Obsesif-kompulsif bozukluk, TSSB: Travma sonrası stres bozukluğu, BTA: Başka türlü adlandırılamayan, IBS: İrritabl bağırsak sendromu

ölçümlerinde de sürdürüldüğü belirtilmiştir. Bütünleşik Protokol’ün uzun süreli sonuçlarını değerlendirmek amacıyla başka bir çalışmada (Bullis ve ark. 2014) aynı örneklemde tedavisini tamamlayan katılımcıların 15'inden -6 aylık takibe ek olarak- 12 aylık takip ölçümleri alınmıştır. Klinik şiddet, depresyon ve anksiyete belirtileri, olumlu ve olumsuz duygu düzeyleri ve günlük işlevsellik ölçümlerinde 6 ay sonunda gözlemlenen tedavi kazanımlarının 12 aylık takip ölçümü sonuçlarında anlamlı şekilde sürdürüldüğü rapor edilmiştir. Bu çalışma ile tanılar üstü müdahaleyi takiben kazanılan tedavi kazanımlarının devamlılığına dair ilk destekleyici bulgular alanyazında yerini almıştır.

$\mathrm{Bu}$ umut verici sonuçlara dayanarak, Bütünleşik Protokol'ün anksiyete bozukluklarının tedavisinde kullanılan tanıya özgü protokoller kadar etkili olup olmadığı Amerikan Ulusal Ruh Sağlığ Enstitüsü (National Institute of Mental health) tarafindan desteklenen seçkisiz kontrollü bir çalışmada değerlendirilmiştir. Çalışmada Bütünleşik Protokol ile agorafobiyle birlikte görülen ya da agorafobisiz panik bozukluk, yaygın anksiyete bozukluğu, obsesif kompulsif bozukluk ve sosyal anksiyete bozukluğu tanılarına yönelik tanıya özgü standart tedavi manuelleri ve bekleme listesi kontrol grubu karşılaştırılmıştır. Seçkisiz şekilde 3 gruba atanan katılımcılardan Bütünleşik Protokol grubunda olan katılımcıların ( $\mathrm{n}=88)$ standart protokol alan katılımcilara ( $\mathrm{n=91)} \mathrm{kıyasla} \mathrm{müdahaleyi} \mathrm{daha} \mathrm{fazla} \mathrm{tamamlama} \mathrm{eğiliminde}$ oldukları; tüm tedavi gruplarındaki katılımcılardan alınan akut sonuçlarda bekleme listesindekilere ( $n=44)$ kıyasla anlamlı bir iyileşme gösterdikleri rapor edilmiştir. Öte yandan, ön-test ölçümlerine kıyasla son-test ve 6 aylık takip ölçümlerinde görülen klinik şiddetteki azalmalarda hem Bütünleşik Protokol hem de standart protokoller arasında istatiksel olarak anlamlı farklılık bulunmamıştır. Sonuçlardan yola çıkarak Bütünleşik Protokol'ün daha az katılımcı kaybı ile anksiyete bozukluklarının tedavisinde standart kanıta dayalı psikolojik müdahalelerle eşit iyileşme sağladığı belirtilebilir. Hatta bu çalışma sonucunda sıklıkla birlikte görülen anksiyete ve depresif bozukluklarını daha etkili bir şekilde tedavi etmek için çoklu 
standart protokoller yerine tek bir protokolün kullanabileceği ileri sürülmüştür (Barlow ve ark. 2017). Bu öneri doğrultusunda bahsi geçen çalışmada kontrol grubundaki katılımcılar dışlanarak, Bütünleşik Protokol'ün standart protokollere kıyasla birincil tanıya eşlik eden psikolojik bozuklukların tedavisinde etkili olup olmadığı değerlendirilmiştir (Steele ve ark. 2018). 179 katılımcının dahil edildiği çalışmada her iki müdahale grubunda, katılımcıların tanı ortalamaları başlangıca kıyasla tedavi sonunda ve 12 aylık takip ölçümlerinde anlamlı bir düşüş göstermiştir. Sonuçta her iki müdahalenin de eşlik eden psikolojik bozuklukların belirtilerinin azalmasında etkili olduğu ve gruplar arasında anlamlı farklılık olmadığı tespit edilmiştir. Bütünleşik Protokol ile standart protokollerin semptom iyileştirmeye yönelik farklılığı bulunmasa da bu derlemenin giriş kısmında belirtilen tanılar üstü tedavinin klinik, pratik ve ekonomik avantajları vurgulanmıştır.

Bütünleşik Protokol'ün farklı kültürlere uyarlanmasına örnek olarak İran'da yürütülen bir çift körlemeli SKÇ’de depresyon ve anksiyete ölçümlerine göre seçilen 26 kişi kontrol ve müdahale gruplarına atanmıştır. Çalışmanın birinci amacı olarak Bütünleşik Protokol'ün depresif ve anksiyete belirtileri üzerindeki etkisi değerlendirilmiş ve müdahale grubunda olan kişilerin kontrol grubundakilere kıyasla anksiyete ve depresif belirtilerinde azalma gözlendiği bildirilmiştir. Ayrıca duygu düzenlemenin tedavi sonuçları üzerindeki etkisi açısından Bütünleşik Protokol'ün depresif ve anksiyete belirtileri üzerindeki etkisinin duygu düzenlemedeki iyileşme aracılığıyla sağlandığı belirtilmiştir (Khakpoor ve ark. 2019).

\section{Eşlik eden depresyon ve anksiyete bozuklukları üzerindeki etkisi}

Bütünleşik Protokol'ün duygularla ilişkili birçok bozukluğun gelişimi ve devamında önemli rol oynayan duygu düzenleme süreçlerini hedef alması, protokolün farklı örneklem gruplarında da çalışılmasına olanak sağlamıştır. Bu bağlamda, bu protokolün eşlik eden duygularla ilişkili bozukluklarda da etkisinin ayrıca incelendiği görülmektedir. Örneğin alanyazında yüksek oranda komorbidite ve işlevsel bozukluk ile ilişkili beden dismorfik bozukluğun tedavisinde BDT etkili olsa da pek çok çalışma duygu düzenlemenin bu bozuklukta temel bir eksiklik olduğunu bizlere göstermektedir. Bu kapsamda, beden dismorfik bozukluğu tanı kriterlerini karşılayan 128 hasta ile yürütülen bir çalışmada (Mohajerin ve ark. 2019) katılımcılar seçkisiz bir şekilde Bütünleşik Protokol ya da her zamanki tedavi koşuluna atanmıştır. Kontrol grubundaki 30 katılımcı ilaç tedavilerine devam etmiş ve haftalık psikiyatristleriyle ilaç devamlılı̆̆ı konusunda görüşmeleri sağlanmıştır. Araştırma sonucunda Bütünleşik Protokol'ün kontrol grubuna kıyasla büyük etki boyutlarıla birlikte duygu düzenlemede anlamlı iyileşmeler sağlayarak depresyon düzeyini ve bunun yanı sıra beden dismorfik bozukluğu belirtilerini ve bedenle ilişkili anksiyeteyi anlamlı şekilde azalttığı bulunmuştur. Ayrıca tedavi kazanımlarının değerlendirildiği 3 aylık takip değerlendirmesinde bu değişimin korunduğu rapor edilmiştir. Bu çalışma beden disformik bozukluğunun tedavisinde Bütünleşik Protokol kullanımını ilk kez incelemekle birlikte, araştırma bulguları bu bozuklukla diğer duygularla ilişkili bozuklukların ortak mekanizmaları paylaştığı ve Bütünleşik Protokol'ün bu duruma yönelik etkili bir ek tedavi 
olabileceği fikrini desteklemiştir.

Bütünleşik Protokol'ün farklı örneklem gruplarında etkinliğini değerlendiren başka bir çalışma (Ellard ve ark. 2017) bipolar bozukluğuna eşlik eden anksiyete bozukluğu tanılı bireylerin tedavisinde Bütünleşik Protokol'ün etkinliğini incelemiştir. Bipolar bozukluk ve en az bir eşlik eden anksiyete bozukluğu tanısı olan 29 katılımcı seçkisiz bir şekilde ilaç tedavisi ya da buna ek olarak Bütünleşik Protokol gruplarına atanmıştır. İlaç tedavisine ek olarak Bütünleşik Protokol müdahale grubunda olan katılımcıların zaman içinde anksiyete ve depresyon belirtilerinde anlamlı bir şekilde daha fazla azalma rapor edilmiştir. Bipolar bozuklukta da görülebilen intihar düşünceleri ve davranışlarına yönelik Bütünleşik Protokol'ün uygulandığı başka bir çalışmada (Bentley ve ark. 2017), yakın zamanlardaki bir intihar girişimini veya aktif intihar düşüncesini bildiren, yatarak tedavi gören bireylerde Bütünleşik Protokol her zamanki tedaviye eklenmiştir. Az sayıda olsa da, 12 katılımcı seçkisiz bir şekilde her zamanki tedavi veya buna ek olarak Bütünleşik Protokol gruplarına atanmıştır. Çalışma bulguları her zamanki tedaviye Bütünleşik Protokol'ün eklenmesinin uygulanabilirliğine ve kabul edilebilirliğine işaret ederken, bu uygulama intihar girişimi ya da düşünceleri olan bireylerin tedavisinde bilişsel-davranışçı ve duygu odaklı tedavinin umut verici bir girişim olabileceği düşüncesini de desteklemektedir.

Çiftlemesine kör, seçkisiz, plasebo kontrollü desenin kullanıldığı bir diğer çalışmada (Ciraulo ve ark. 2013) dahil edilme kriterlerini karşılayan katılımcılar dört tedavi koşulundan birine seçkisiz bir şekilde atanmıştır: venlafaksin + Bütünleşik Protokol ( $n=24)$, Placebo + Bütünleşik Protokol ( $n=21)$, venlafaksin + Gevşeme ( $n=14)$, Placebo + Gevşeme ( $n=22)$. Ağır alkol tüketimi açısından plasebo + Bütünleşik Protokol ile placebo + gevşeme gruplarının karşılaştırılması sonucunda placebo + Bütünleşik Protokol grubundaki katılımcıların günlük alkol tüketme yüzdelerinde daha yüksek oranda azalma rapor edilirken, diğer gruplar ile karşılaştırma grubu arasında anlamlı bir farklılık bulunmamıştır. 11. haftada placebo + Bütünleşik Protokol grubundaki günlük alkollü içki içme yüzdesi ilk ölçümden \%50 oranında azalma gösteren katılımcıların oranının kontrol grubuna kıyasla anlamlı olarak daha fazla olduğu gözlenmiştir. Bu bulgu Barlow ve meslektaşlarının tanılar üstü yaklaşımının, eşlik eden alkolizm ve anksiyete bozukluğu olan bireylerde aşırı alkol tüketiminin yönetiminde etkili olabileceğini önermektedir.

Duygularla ilişkili bozukluklarla ortak faktörleri paylaştığ önerilen diğer bir psikolojik sorun olan uykusuzluğun depresif ve anksiyete belirtilerini artırdığ1 görüşünden hareketle, uykusuzluk ve eşlik eden duygularla ilişkili bozukluğa sahip olan küçük bir örneklemde (Vand ve ark. 2018) Bütünleşik Protokol'ün tanılar üstü faktörler olarak davranışsal inhibisyon/ davranışsal aktivasyon, anksiyete duyarlılı̆̆ı, duygu düzenleme güçlüğü ve aynı zamanda uykusuzluğa özel biliş ve davranışlar üzerindeki etkileri değerlendirilmiştir. Denekler arası çoklu başlama deseninin kullanıldığı çalışmada 6 katılımcıdan 14 haftalık bireysel Bütünleşik Protokol seanslarını takiben 3 aylık takip ölçümü alınmıştır. Çalışmanın sonuç ölçümleri için davranışsal inhibasyon/davranışsal aktivasyon, anksiyete duyarlılığı, duygu düzenleme güçlüğü, uyku ile ilgili işlevsel olmayan inançlar, tutumlar ve uyku ile ilişkili davranışları değerlendiren ölçeklerden yararlanılmıştır. Katılımcıların tedavi öncesine kıyasla, tedavi 
sonunda alınan sonuç ölçümlerinde anlamlı değişimler gösterdiği ve bu değişimin 3 aylık takip ölçümlerinde de sürdüğü bildirilmiştir. Ön çalı̧̧ma olarak görülebilecek bu araştırma, duygularla ilişkili bozukluklarla birlikte görülen kronik uykusuzlukta da Bütünleşik Protokol'ün yararına ilişkin görgül kanıtlar sunmaktadır.

Eşlik eden psikolojik rahatsızlıklara ek olarak bazı fiziksel rahatsızlıkların şiddetini ve bu rahatsızlıkların yol açtığ 1 işlevsellik alanlarındaki sorunların azaltılmasına yönelik Bütünleşik Protokol'ün etkinlik çalışmaları da alanyazında yer almaktadır. Bu rahatsızlıklardan biri olan ve çeşitli psikolojik sorunların eşlik ettiği irritabl bağırsak sendromuna (IBS) odaklı bir SKÇ’de (Mohsenabadi ve ark. 2018) IBS tanılı 64 katılımcı 12 haftalık Bütünleşik Protokol tedavi grubuna ya da bekleme listesi kontrol grubuna atanmıştır. Müdahale sonrası tedavi grubundaki katılımc1ların hem depresyon, anksiyete, stres ve gastrointestinal belirtilerinde hem de duygu düzenleme puanlarında anlamlı değişimler olduğu rapor edilmiştir. Ayrıca bu çalı̧̧ma sonucunda duygu düzenlemedeki değişimlerin Bütünleşik Protokol'ün duygusal ve gastrointestinal semptomlarındaki değişikler üzerindeki etkisine aracılık ettiği desteklenmiştir. Son olarak, depresyon için yüksek risk grubunda olan meme kanseri hastaları için kanser sonrası depresyonu önleme için orijinal Bütünleşik Protokol'den uyarlanan müdahale değerlendirilmiştir. Bütünleşik Protokol'ün yakın zamanda meme kanseri teşhisi alan 15 katılımcıda uygulanmasını inceleyen çalışmanın sonuçları bireysel olarak yürütülen bu önleyici müdahale programının uygulanabilirliğini desteklemiştir (Weihs ve ark. 2019).

\section{Grup olarak uygulanan protokoller}

Bütünleşik veya tanılar üstü müdahale programları ayrıca grup formatında da uygulanabilmektedir. Hatta bu tür programlardan biri anksiyete bozukluklarına özgü geliştirilen Tanılar Üstü Bilişsel Davranışçı Grup Terapisi'dir. Benzer şekilde, yapılan alanyazın taramasında görgül çalışmaların bir kısmı bu yaklaşımı temel almıştır. Örneğin farklı anksiyete bozukluğu tanıları olan 23 katılımcının seçkisiz bir şekilde müdahale ve bekleme listesi kontrol grubuna atandığı bir çalışmada, müdahale grubunda yer alan katılımcılarda tanıya yönelik ölçümlerinde ve korku-kaçınma hiyerarşilerinde daha fazla anlamlı iyileşme gözlenmiştir (Norton ve Hope 2005). Aynı katılımcıların depresif duygu durumları incelenmiş ve yine kontrol grubuna kıyasla tanılar üstü tedavi alan katılımcıların depresif duygu durumunda anlamlı azalmalar olduğu rapor edilmiştir (Norton ve ark. 2004). Bu tedavinin özellikle panik bozukluk ve sosyal fobi olmak üzere farklı anksiyete bozuklukları üzerindeki etkisini karşılaştırılan bir diğer çalışmada ise katılımcıların tedavi boyunca iyileşme eğiliminde oldukları bulunmuştur. Bu çalışmanın bulguları farklı anksiyete bozukluklarına sahip kişilerin aynı tedavi protokolü ile tedavi edilebileceği varsayımını destekler nitelikte görünmektedir (Norton 2008).

Gevşeme eğitimi ile bu grup tedavisinin karşılaştırıldı̆̆1 seçkisiz kontrollü bir çalışmada gruplara atanan katılımcıların tedavi sonuçları arasında anlamlı farklılık bulunmamakla birlikte, gevşeme grubunda tedaviyi yarıda bırakma oranları daha yüksektir (Norton 2012). Bozukluklara özgü 12 haftalık BDT grup tedavisi ile tanılar üstü grup terapisinin karşılaştırıldığı seçkisiz kontrollü bir çalışmada her iki grupta yer alan katılımcıların tedavi 
boyunca anlamlı iyileşmeler gösterdikleri ve müdahalelerin etkinliğinde farklılık olmadığ 1 bulunmuştur. $\mathrm{Bu}$ araştırma ile tanılar üstü grup tedavisinin etkinlikten ödün vermeden anksiyete bozuklukları için kanıta dayalı tedavilere erişimi artırma yararına sahip olduğunu söylenmiştir (Norton ve Barrera 2012).

Barlow ve ekibinin geliştirdiği Bütünleşik Protokol bireysel olarak uygulandığında heterojen anksiyete ve eşlik eden depresif bozukluklara sahip bireylerde umut verici sonuçlar gösterdikten sonra grup formatındaki uygulamalarla da olumlu sonuçlar gösterip göstermeyeceği merak konusu olmuştur. Bu merakla yürütülen öncü araştırmalardan ilkinde çeşitli tanılara sahip 11 katılımcı ile ön-son test desende grup formatında yürütülen bu protokolün anksiyete ve depresif belirtiler, işlevsel bozukluk, yaşam kalitesi ve duygu düzenleme becerileri üzerinde iyi düzeyde etkiye sahip olduğu; aynı zamanda katılımcıların yüksek düzeyde memnuniyet rapor ettiği bildirilmiştir. Hatta grup formatındaki uygulamanın bulgularının neredeyse bireysel uygulama sonuçlarına eş değer olarak görülebileceği de eklenmiştir (Bullis ve ark. 2015). Bütünleşik Protokol'ün etkisini değerlendiren başka bir çalışmada anksiyete bozukluklarına sahip 47 katılımcıda bozukluk şiddeti, anksiyete ve psikolojik iyi oluş düzeylerinde klinik olarak anlamlı değişimler rapor edilmiştir. Bunun yanı sıra eşlik eden depresif belirtiler ile olumlu ve olumsuz duygu seviyelerinde tedavi sonrası anlamlı değişimler gözlenmiştir. Bulgular Bütünleşik Protokol'ün oldukça yüksek komorbidite vakalarında anksiyete ve depresif belirtiler üzerinde olumlu etkilerini göstererek, ruh sağlığı hizmetlerinde grup formatında başarılı bir şekilde uygulanabileceğini göstermiştir (Reinholt ve ark. 2017).

Depresyon ve anksiyete bozukluklarına sahip hastalarda grup formatı şeklinde uygulanan Bütünleşik Protokol'ün etkisini değerlendiren bir çalışmada 48 katılımcı iki gruba ayrıştırılmıştır. Gruplardan birine 12 seanslık Bütünleşik Protokol uygulanırken, diğer gruptaki katılımcılara yalnızca ilaç tedavisi verilmiştir. Bütünleşik Protokol yalnızca ilaç tedavisi verilen gruptaki katılımcılarla karşılaştırıldığında, katılımcıların depresif ve anksiyete bozukluklarının iyileşmesinde oldukça etkili olduğu rapor edilmiştir. Örneklem sayısının küçük olması ve gruplara atamanın seçkisiz bir şekilde yapılmaması araştırma sonuçlarının genellenebilirliğini kısıtlasa da tanılar üstü tedavide grup formatının kullanımına yönelik daha geniş örneklemli, seçkisiz kontrollü çalışmalara örnek teşkil etmiştir (de Ornelas Maia ve ark. 2015). Bütünleşik Protokol, Klasik BDT grup tedavisi ile seçkisiz bir araştırma deseninde karşılaştırıldığında tedavi öncesi ve sonrası depresyon, anksiyete, stres, iş ve sosyal uyum değerlendirmelerinde her iki grupta da ön testlere göre son testte anlamlı değişiklikler görülürken, Bütünleşik Protokol ve standart BDT karşılaştırıldığında ise anksiyete haricinde diğer tüm değişkenlerde anlamlı farklılık olmadığı rapor edilmiştir. Diğer bir deyişle, her iki yöntem de işe yaramış, fakat tanılar üstü grup terapisi ayrıca anksiyete belirtilerinin azalmasında anlamlı bir farklılık sergilemiştir (Mohammadi ve ark. 2013).

Eşlik eden psikolojik bozukluklara sahip kişiler sıklıkla işlevsellik alanlarında birtakım sorunlarla karşılaşırlar ve yaşam kalitelerinde ciddi anlamda bir düşüş deneyimlerler. Bütünleşik Protokol'ün iyileşmiş duygu düzenleme aracılığıyla psikolojik bozuklukların yol açtığı ek sıkıntıları giderme potansiyeline de sahip olduğu önerilmiştir. Bu varsayımı test 
etmek amacıyla tasarlanan bir çalışmada eşlik eden psikolojik bozukluklara sahip bireylerde grup formatında uygulanan Bütünleşik Protokol'ün cinsel işlev bozukluğu ve düşük yaşam kalitesi üzerindeki etkileri değerlendirilmiştir. SKÇ türü bir çalı̧̧mada Bütünleşik Protokol ile ilaç tedavisi grubu kıyaslanmış; bütünleşik müdahale alan grupta yaşam kalitesi, anksiyete ve depresyon belirtilerinin tümünde anlamlı bir şekilde iyileşme rapor edilmiştir. Ayrıca, tedavi öncesine kıyasla tedavi sonrası cinsel işlevlerde de bir iyileşme gözlenmiştir (de Ornelas Maia ve ark. 2017).

\section{İnternet destekli protokoller}

$\mathrm{Bu}$ derleme için yapılan taramada anksiyete ve/veya depresyon tanılı yetişkin katılımcılara yönelik internet üzerinden uygulanan protokollerin etkisinin incelendiği görgül çalı̧̧malarla da karşılaşılmıştır. Bunlardan bir tanesinde internet destekli Bütünleşik Protokol'ün etkinliğini değerlendirmek amacıyla seçkisiz olarak 105 katılımcı aktif tedavi grubuna ya da bekleme listesi kontrol grubuna atanmıştır. Kontrol grubuna kıyasla, tanılar üstü müdahalenin anksiyete ve depresif belirtilerin yanı sıra anksiyete duyarlılı̆̆ı ve yaşam kalitesi üzerinde de olumlu etki gösterdiği ve dolayısıyla, bu tür müdahalelerin internet yoluyla da etkili bir tedavi seçeneği olabileceği önerilmiştir (Tulbure ve ark. 2018).

Birden fazla anksiyete bozukluğunu tedavi etmeye yönelik geliştirilmiş tanılar üstü internet temelli BDT programının (the Anxiety Program) etkinliğini değerlendiren başka bir çalışma da farklı anksiyete bozukluğu tanıları olan katılımcıların yer aldığı bir SKÇ’dir (Titov ve ark. 2010). BDT temelli çevrimiçi eğitici ders ve ödevler, bir klinik psikolog tarafindan yürütülen haftalık e-posta veya telefonla iletişim, moderatörlü bir çevrimiçi tartışma forumuna erişim ve otomatik e-postalardan oluşan 8 haftalık müdahaleyi tedavi grubundaki katılımcıların \%75’i tamamlamıştır. Kontrol grubuna kıyasla, tedavi grubundaki katılımcıların anksiyete belirtilerinde anlamlı bir şekilde azalma görülmüş ve takip ölçümlerinde tedavi kazanımlarını önemli ölçüde korudukları gözlenmiştir.

Anksiyete bozukluklarını ve depresyonu aynı programla tedavi etmek amacıyla geliştirilmiş internet temelli tanılar üstü bir başka BDT programının (the Wellbeing Program) etkinliğinin değerlendirildiği kontrol gruplu seçkisiz bir çalı̧mada, depresyon ve anksiyete bozukluğu olan katılımcılar 10 haftalık tedavi programını tamamlamıştır. Kontrol grubuna kıyasla, müdahale grubundaki katılımcıların anksiyete ve depresyon belirtilerinde anlamlı bir şekilde azalma görülmüş ve bu değişimin 3 aylık takip ölçümlerinde sürdüğü rapor edilmiştir (Titov ve ark. 2011). Hatta bu programın kısa versiyonunun etkisinin değerlendirildiği başka bir çalışmada majör depresyon, yaygın anksiyete bozukluğu, panik bozukluk ve/ veya sosyal fobi tanılı 32 katılımcıda depresif ve anksiyete belirtilerinde anlamlı bir şekilde değişim gözlenmiştir. Bu değişim 3 aylık takip ölçümlerinde de sürmektedir (Dear ve ark. 2011). Benzer şekilde, diğer bir tanılar üstü ve internet temelli BDT programına katılan 53 katılımcı seçkisiz olarak kontrol ve müdahale gruplarına atanmıştır. Kontrol grubuna kıyasla anksiyete ve depresyon belirtilerinde anlamlı azalmalar göstermiş ve bu azalmanın 3 ay sonra da devam ettiği bildirilmiştir (Mullin ve ark. 2015). Son olarak, internet destekli tanılara özgü ve tanılar üstü programların karşılaştırıldığı bir diğer çalışma her ne kadar seçkisiz 
olmasa da her iki programın depresyon ve yaygın anksiyete bozukluğu için benzer düzeyde etki gösterdiğini bulmuştur (Newby ve ark. 2017).

İnternet destekli tanılar üstü tedavi programındaki terapist özellikleri de merak konusudur. Destek veren kişinin tedaviye etkisinin incelendiği bir çalışmada yaygın anksiyete bozukluğu tanısı olan 131 katılımcı seçkisiz bir şekilde üç gruba atanmıştır. Terapistin ve eğitmenin destek verdiği gruplardaki katılımcıların anksiyete ve depresif ölçümlerinde kontrol grubundakilere kıyasla daha iyi sonuçlar görülse de, terapist destekli grupta sonuçlar takip ölçümleri de dahil olmak üzere daha iyidir (Johnston ve ark. 2011). Aynı örneklem eş tanı açısından incelendiğinde eş tanısı olan katılımcılar tedavi öncesi, sonrası ve takip sürecinde daha yüksek belirti rapor etse de, müdahale programı sonrasında eş tanılı insanların sorunlarında azalmanın daha belirgin olduğu bildirilmiştir (Johnston ve ark. 2013). Benzer şekilde, 458 katılımcının ruh sağlığı kliniği veya genel sağlık kliniğinde çalışan terapistlerin destek verdiği gruplara atandığı bir çalışmadaki karşılaştırma sonucunda (Hadjistavropoulos ve ark. 2016), her iki grupta da tedaviyi tamamlama oranlar1, memnuniyet seviyeleri, anksiyete ve depresyon düzeylerinde anlamlı değişimler yaşanırken gruplar arası anlamlı bir fark olmadığ1 görülmüş; bu tür programlar yapılandırılmış ve standardize olduğu için terapist etkisinin görece az olabileceği tartı̧̧1mıştır.

Hadjistavropoulos ve ark. (2017) tarafindan yürütülen 8 haftalık tanılar üstü internet destekli BDT programından elde edilen verilerden faydalanılarak sağlık anksiyetesi belirtilerindeki değişiklikler araştırılmıştır. Tedavi öncesinde Kısa Sağlık Anksiyetesi Envanteri'nden (the Short Health Anxiety Inventory) yüksek puan alan alt örneklem grubunda tedavi sonrası sağlık anksiyetesi, depresyon, yaygın anksiyete belirtilerinde anlamlı azalmalar olduğu rapor edilmiştir (Owens ve ark. 2019). Fiziksel bir kökeni bulunamayan sindirim sistemi rahatsızlıkları olan kişilere yönelik uygulanan tanılar üstü ve internet destekli BDT müdahalesinin (the Chronic Conditions Course) incelendiği bir çalışmada (Dear ve ark. 2018) katılımcıların sindirim sistemi şikayetleri ile anksiyete ve depresyon belirtilerinde anlamlı iyileşmeler olduğu rapor edilmiş ve bu durum 3 aylık takip ölçümünde korunmuştur.

\section{Tartışma}

Bu sistematik derleme çalışmasının öncelikli amacı eş-tanı bozukluklarının aynı anda tedavi edilmesine olanak sağlayan ve başta depresyon ve anksiyete olmak üzere duygularla ilişkili çeşitli bozukluklara yönelik tanılar üstü tedavilerin etkisini araştıran görgül çalı̧̧maları sistematik bir şekilde derlemektir. Bu amaçla ilgili alanyazın incelenmiş ve belirlenen dahil edilme-çıkarılma ölçütleri doğrultusunda toplam 31 çalışmaya ulaşılmıştır. Elde edilen çalışmalar araştırma amacı, örneklem özellikleri, yöntemsel arka plan ve araştırma bulguları açısından gözden geçirilmiştir.

Genel olarak bakıldığında alanyazında bu konuda temelde iki ana programa yönelik görgül çalışmalar yapıldığı görülmektedir. Bunlardan ilki olan Bütünleşik Protokol'ün çeşitli duygularla ilişkili bozuklukların tedavisinde etkinliğine dair güçlü görgül bulgular elde edildiği söylenebilir. İlk olarak 2014 yılında bu amaçla yapılan günümüze kadar seçkisiz veya 
seçkisiz olmayan pek çok kontrollü araştırma sonuçları, bireysel olarak uygulanan Bütünleşik Protokol'ün kontrol grubuyla karşılaştırıldığında çeşitli anksiyete bozukluklarının belirti şiddetini anlamlı bir şekilde azalttığı görülmektedir., Bununla beraber tedaviden 3-18 ay sonrası takip ölçümlerinde de katılımcılardaki bu iyileşmenin devam ettiği söylenebilir. Ayrıca duygularla ilişkili bozuklukların tedavisinde Bütünleşik Protokol ve tanıya özgü protokoller uygulanan hasta gruplarında, genel anlamda, benzer düzeyde belirti iyileşmesi rapor edildiği görülmektedir. Öte yandan her iki grup da tedavi sonrası birincil tanı şiddetinde önemli azalmalar gösterirken, Bütünleşik Protokol uygulamalarında tanıya özgü protokollerden daha az sayıda tedaviyi yarıda bırakma durumu bildirilmiştir. Bütünleşik Protokol'ün eşlik eden bozukluklar açısından da önemli faydalarının olduğu ve iyileşmelerin 1 yıl sonra da sürdüğü rapor edilmiştir. Bütünleşik protokol gibi tanılar üstü bilişsel-davranış̧̧1 müdahaleler geleneksel BDT'nin birçok unsurundan faydalandığ 1 için, anksiyete ve depresif belirtilerin bir arada olduğu durumlarda önemli avantajlar sağlayabileceği önerilmektedir (Bell ve ark. 2016).

Bütünleşik Protokol'ün belirli avantajlarından ötürü (aynı anda daha fazla kişiye ulaşma, tedavi arayışı ile ilişkili damgalanmanın önüne geçme ve etkileşim sayesinde diğer katılımcıların deneyimlerinden faydalanma gibi) grup formatında da uygulanarak incelendiği görülmektedir. İkisi seçkisiz kontrollü bir şekilde yürütülen toplam 6 çalışmadan elde edilen bulgular, Bütünleşik Protokol'ün anksiyete ve depresif belirtiler, işlevsel bozukluk, yaşam kalitesi ve duygu düzenleme becerileri üzerinde olumlu yönde etkileri olduğunu göstermiştir. Buna ek olarak, Bütünleşik Protokol'ü grup formatında alan bireyler, bireysel uygulamaya katılanlarla benzer düzeyde memnuniyet bildirmişlerdir (Bullis ve ark. 2015). Benzer şekilde, grup formatında anksiyete bozuklukları için geliştirilen Tanılar Üstü Bilişsel-Davranış̧̧ Grup Tedavisinin (Norton ve Hope 2005) etkisinin değerlendirildiği 4'ü seçkisiz kontrollü olmak üzere bu çalışmada yer alan 5 çalışmadan elde edilen bulgular ile paralellik göstermektedir. Her iki protokolün grup formatı ile uygulanmasına yönelik yapılan tüm çalışmalarda karşılaştırma grubu olarak bekleme listesi-kontrol grubunun kullanıldı̆̆ görülmektedir. Tanılar üstü bilişsel-davranışçı grup tedavisinin etkinliği sadece bir seçkisiz kontrollü çalışmada tanıya özgü BDT protokolleriyle karşılaştırılmıştır (Norton ve Barrera 2012). Bu çalışma, tanılar üstü bilişsel-davranış̧̧ı grup terapisinin anksiyete belirtileri üzerindeki etkisinin tanıya özgü BDT protokollerinin etkisine göre daha düşük olmadığını tespit etmiştir. Bütünleşik ya da tanılar üstü bilişsel-davranışçı grup tedavi protokolleri ile tanıya özgü protokolleri doğrudan karşılaştıran çalışmaların sınırlı sayıda olması nedeniyle, gelecekte bu karşılaştırmalara olanak sağlayan seçkisiz kontrollü çalışmalara ihtiyaç göze çarpmaktadır.

Kanıta dayalı tedavilere erişimi artırmak için kullanılan yöntemlerden biri olan tanıya özgü internet tabanlı BDT tedavilerinin ise, anksiyete ve depresif bozukluklarda etkili olduğu ve yüz yüze tedavilere benzer sonuçlar ürettiği belirtilmektedir (Cuijpers ve ark. 2009). Aynı sonuçların internet destekli tanılar üstü BDT protokollerinden elde edilip edilmeyeceğine dair yapılan son dönemki araştırmalar, internet destekli tanılar üstü tedavilerin depresyon ve anksiyete bozukluklarındaki etkisine dair destekleyici bulgular sunmaktadır (Dear ve ark. 
2011, Johnston ve ark. 2011, Titov ve ark. 2010, 2011). Bu araştırmalar doğrultusunda bu programların birincil tanıları depresyon ve anksiyete bozukluğu olan veya eşlik eden bu tür sorunları olan bireylerde internet üzerinden de olumlu etki oluşturduğu söylenebilir. Eşlik eden tanısı olan ve olmayan katılımcılar için gözlemlenen tedavi kazanımlarının, bu yaklaşımının ekonomik ve uygulama açısından avantajlarının yanında nispeten daha az uzmanla temas ile elde edildiğini belirtmek de önemlidir. Yine de bu sonuçlar, gelecekteki araştırmaların odaklanması gereken birkaç önemli konuyu ortaya çıkarmaktadır. İlk olarak, çalışmalarda internet destekli tanılar üstü müdahalelerin etki karşılaştırılmaları genellikle bekleme listesi kontrol grubu ile yapılmıştır. Dolayısıyla, tanıya özgü tedavi protokollerini tanılar üstü protokollerle karşılaştırmak, psikoterapötik tedavi araştırmalarının önemli bir hedefi olan değişimin temel mekanizmaları hakkında tartışmaya ve bilgiye katkıda bulunacaktır (Kazdin 2007). Ayrıca hangi birincil veya komorbid bozuklukların tanılar üstü tedaviye yanıt verdiği konusunda önemli sorular da vardır. Yaygın anksiyete bozukluğu, sosyal anksiyete, panik bozukluk ve depresyon belirtilerini tedavi etmek için internet destekli tanılar üstü BDT protokollerinin etkinliği için kanıt sunulmasına rağmen (Titov ve ark. 2011) travma sonrası stres bozukluğu, obsesif-kompulsif bozukluk gibi diğer bozuklukların da internet tabanlı tanılar üstü müdahaleler ile tedavi edilip edilemeyeceği hala belirsizliğini korumaktadır. İnternet destekli tanılar üstü protokollerin tanıya özgü protokollerle kıyaslanması ve tanılar üstü yaklaşımın farklı tanı gruplarındaki etkinliğinin değerlendirilmesi gelecek çalışmaların önemli konuları arasında yer almaktadır.

Bireysel, grup temelli ya da internet destekli formatlardaki kullanımının değerlendirildiği çalışmaların birçoğunda, karşılaştırmanın bekleme listesi kontrol grubu veya her zamanki tedavi grubu ile yapıldığı, çalışmalarda zaman zaman az sayıdaki katılımcının yer aldığını belirtmek gerekir. Ayrıca bütünleşik ya da tanılar üstü protokolleri tanıya özgü protokoller ile karşılaştıran çok az sayıda seçkisiz kontrollü çalı̧̧ma bulunmaktadır. Bu tür etki çalışmalarında tanılar üstü protokollerin tanıya özgü protokoller kadar etkili olduğu sonucuna varılsa da, özellikle tanılar üstü yaklaşımdan potansiyel olarak en fazla kimin yarar sağlayabileceğini belirlemede ek çalışmalara ihtiyaç vardır. Bütünleşik Protokol ve Tanılar üstü Bilişsel-Davranışçı Grup Terapisi gibi müdahaleler hem danı̧̧anlar hem de terapistler için birçok pratik avantajı bünyesinde barındırmaktadır. Daha önceden bahsedildiği gibi, psikolojik bozukluklar arasındaki birlikte görülme oranlarının oldukça yüksek olması ve tanıya özgü müdahalelerin komorbid durumları ele almak için yeterli donanıma sahip olmaması tedaviyi zorlaştırmaktadır. Ek olarak, terapistlere neredeyse her bir bozukluk için ayrı tedavi protokollerini uygulamak ekonomik yük oluşturmaktadır. Bu sebeple, tanılar üstü müdahalelerin etkinliğini ve tanıya özgü protokollere kıyasla olası klinik ve ekonomik avantajlarını araştırmanın önemi, özellikle tanıya özgü protokollerin uygulanmasının zor olduğu gerçeği ya da tedaviye erişmede güçlük yaşayan kişilere ulaşım açısından apaçık ortadadır (Reinholt ve Krogh 2014).

Genel olarak, anksiyete veya depresif bozukluklar için tanılar üstü yaklaşımların etkinlik çalışmalarının çoğu Batı ülkelerinde yapılmıştır. Bu durum, çalışma bulgularının farklı kültürel bağlamlara genellenebilirliği açısından önemli bir kısıtlllık oluşturmaktadır. 
Dolayısıyla, tanılar üstü protokollerin adaptasyonu ve etkinlik çalışmalarının Batı ülkeleri dışında diğer kültürlerde de sınanmasını gereklidir. Bütünleşik Protokol'ün anksiyete ve depresif belirtiler üzerindeki etkinliğinin Asya kültüründe incelendiği bir çalışmada umut verici sonuçlar ortaya çıkarmıştır (Ito ve ark. 2016). Ülkemizde tanılar üstü yaklaşımın etkinliğine dair bir çalışma bulunmamakla birlikte hem komorbidite durumlarında hem de tedaviye erişimi artırmada etkin olabileceği düşünülen bu yaklaşımın Türkiye kültüründe incelenmesinin önemli olduğu düşünülmektedir.

\section{Sonuç}

$\mathrm{Bu}$ gözden geçirme çalışması kapsamında incelenen araştırmalar genel olarak değerlendirildiğinde, tanılar üstü BDT müdahalelerinin özellikle YAB, sosyal fobi, panik bozukluk ve agorafobi gibi çeşitli anksiyete bozuklukları ve depresyonun tedavisinde etkili olduğu bulunmuştur. Anksiyete ve depresif belirtilerin bir arada olduğu durumlarda tanılar üstü yaklaşımın, tanıya özgü protokollere kıyasla hem danışanlar hem de terapistler açısından önemli avantajlar sağlayabileceği söylenebilir. Daha önce belirtildiği gibi, duygularla ilişkili bozukluklar arasındaki komorbidite oranı oldukça yüksektir ve tanıya özgü protokollerin bu durumu ele almada donanımı yeterli değildir. Ayrıca, yüksek komorbidite durumu tedavi kararında da önemli bir sıkıntı teşkil etmektedir. Komorbidite durumları için etkili olan tek bir protokolün öğrenilmesi ile çok çeşitli tanıya özgü protokollerin eğitim ve maliyet açısından oluşturduğu yük de hafifletilebilir. Diğer yandan, tanıya özgü tedavilerin dayandığg tanısal sınıflandırmaların güvenirliği ve geçerliğinde bulunan bazı kısıtlamalara (tanı kategorileri içinde önemli ölçüde heterojenlik, rahatsızlıklar arasındaki ayrımın zorluğu ve başka türlü adlandırılamayan tanıların yüksek oranda olması gibi) yönelik iyileşmeler sağlayabileceği ve tedaviye erişimi artırabileceği önerilmektedir. Gelecek çalışmalarda tanılar üstü yaklaşımın farklı tanı gruplarında (örn. obsesif-kompulsif bozukluk, travma sonrası stres bozukluğu) tanıya özgü tedavilere kıyasla etkisinin incelenmesinin önemli olduğu sonucuna varılmıştır. Ülkemizde de tanılar üstü müdahalelerin etkinliğini ve tanıya özgü protokollere kıyasla olası klinik ve ekonomik avantajlarını araştırmanın önemli olduğu düşünülmektedir.

\section{Kaynaklar}

APA (2013) Diagnostic and Statistical Manual of Mental Disorders, 5th ed. Washington, DC, American Psychiatric Association.

Barlow DH (2004) Anxiety and its disorders:The nature and treatment of anxiety and panic. New York, Guilford Press.

Barlow DH, Ellard KK, Fairholme CP, Farchione CP, Boisseau CL, Allen LB et al. (2011) The unified protocol for transdiagnostic treatment of emotional disorders: Client workbook. Oxford, Oxford University Press.

Barlow DH, Farchione TJ, Bullis JR, Gallagher MW, Murray-Latin H, Sauer-Zavala S et al. (2017) The unified protocol for transdiagnostic treatment of emotional disorders compared with diagnosis-specific protocols for anxiety disorders: A randomized clinical trial. JAMA Psychiatry, 74:875-884.

Bell C, Jordan J, Alexander A (2016) Transdiagnostic psychological treatments for anxiety and depression. Aust NZJ Psychiatry, 50:201202.

Bentley KH, Sauer-Zavala S, Cassiello-Robbins CF, Conklin LR, Vento S, Homer D (2017) Treating suicidal thoughts and behaviors within an emotional disorders framework: Acceptability and feasibility of the unified protocol in an inpatient setting. Behav Modif, 41:529557.

Brown TA, Barlow DH (2009) A proposal for a dimensional classification system based on the shared features of the DSM-IV anxiety 
and mood disorders: Implications for assessment and treatment. Psychol Assess, 21:256-271.

Bullis JR, Fortune MR, Farchione TJ, Barlow DH (2014) A preliminary investigation of the long-term outcome of the Unified Protocol for Transdiagnostic Treatment of Emotional Disorders. Compr Psychiatry, 55:1920-1927.

Bullis JR, Sauer-Zavala S, Bentley KH, Thompson-Hollands J, Carl JR, Barlow DH (2015) The unified protocol for transdiagnostic treatment of emotional disorders: preliminary exploration of effectiveness for group delivery. Behav Modif, 39:295-321.

Ciraulo DA, Barlow DH, Gulliver SB, Farchione T, Morissette SB, Kamholz BW et al. (2013) The effects of venlafaxine and cognitive behavioral therapy alone and combined in the treatment of co-morbid alcohol use-anxiety disorders. Behav Res Ther, 51:729-735.

Cuijpers P, Marks IM, van Straten A, Cavanagh K, Gega L, Andersson G (2009) Computer-aided psychotherapy for anxiety disorders: A meta-analytic review. Cogn Behav Ther, 38:66-82.

de Ornelas Maia ACC, Nardi AE, Cardoso A (2015) The utilization of unified protocols in behavioral cognitive therapy in transdiagnostic group subjects: A clinical trial. J Affect Disord, 172:179-183.

de Ornelas Maia ACC, Sanford J, Boettcher H, Nardi AE, Barlow D (2017) Improvement in quality of life and sexual functioning in a comorbid sample after the unified protocol transdiagnostic group treatment. J Psychiatr Res, 93:30-36.

Dear BF, Titov N, Schwencke G, Andrews G, Johnston L, Craske MG et al. (2011) An open trial of a brief transdiagnostic internet treatment for anxiety and depression. Behav Res Ther, 49:830-837.

Dear BF, Fogliati VJ, Fogliati R, Gandy M, McDonald S, Talley N et al. (2018) Transdiagnostic internet-delivered cognitive-behaviour therapy (CBT) for adults with functional gastrointestinal disorders (FGID): A feasibility open trial. J Psychosom Res, 108:61-69.

Ellard KK, Bernstein EE, Hearing C, Baek JH, Sylvia LG, Nierenberg AA et al. (2017) Transdiagnostic treatment of bipolar disorder and comorbid anxiety using the Unified Protocol for Emotional Disorders: A pilot feasibility and acceptability trial. J Affect Disord, 219:209221.

Farchione TJ, Fairholme CP, Ellard KK, Boisseau CL, Thompson-Hollands J, Carl JR et al. (2012) Unified protocol for transdiagnostic treatment of emotional disorders: randomized controlled trial. Behav Ther, 43:666-678.

First MB, Rebello TJ, Keeley JW, Bhargava R, Dai Y, Kulygina M et al. (2018) Do mental health professionals use diagnostic classifications the way we think they do? A global survey. World Psychiatry, 17:187-195.

Hadjistavropoulos HD, Nugent MM, Alberts NM, Staples L, Dear BF, Titov N (2016) Transdiagnostic Internet-delivered cognitive behaviour therapy in Canada: An open trial comparing results of a specialized online clinic and nonspecialized community clinics. J Anxiety Disord, 42:19-29.

Hadjistavropoulos HD, Schneider LH, Edmonds M, Karin E, Nugent MN, Dirkse D et al. (2017) Randomized controlled trial of internetdelivered cognitive behaviour therapy comparing standard weekly versus optional weekly therapist support. J Anxiety Disord, 52:1524.

Ito M, Horikoshi M, Kato N, Oe Y, Fujisato H, Nakajima S et al. (2016) Transdiagnostic and transcultural: pilot study of unified protocol for depressive and anxiety disorders in Japan. Behav Ther, 47:416-430.

Johnston L, Titov N, Andrews G, Dear BF, Spence J (2013) Comorbidity and internet-delivered transdiagnostic cognitive behavioural therapy for anxiety disorders. Cogn Behav Ther, 42:180-192.

Johnston L, Titov N, Andrews G, Spence J, Dear BF (2011) A RCT of a transdiagnostic internet-delivered treatment for three anxiety disorders: examination of support roles and disorder-specific outcomes. PloS One, 6:e28079.

Kazdin AE (2007) Mediators and mechanisms of change in psychotherapy research. Annu Rev Clin Psychol, 3:1-27.

Kessler RC, Chiu WT, Demler 0, Walters EE (2005) Prevalence, severity, and comorbidity of 12-month DSM-IV disorders in the National Comorbidity Survey Replication. Arch Gen Psychiatry, 62:617-627.

Khakpoor S, Saed 0, Armani Kian A (2019) Emotion regulation as the mediator of reductions in anxiety and depression in the Unified Protocol (UP) for transdiagnostic treatment of emotional disorders: double-blind randomized clinical trial. Trends Psychiatry Psychother, 41:227-236.

Mennin DS, Heimberg RG, Turk CL, Fresco DM (2005) Preliminary evidence for an emotion dysregulation model of generalized anxiety disorder. Behav Res Ther, 43:1281-1310.

Mohajerin B, Bakhtiyar M, Olesnycky OS, Dolatshahi B, Motabi F (2019) Application of a transdiagnostic treatment for emotional disorders to body dysmorphic disorder: A randomized controlled trial. J Affect Disord, 245:637-644.

Mohammadi A, Birashk B, Gharaie B (2013) Comparison of the effect of group transdiagnostic therapy and group cognitive therapy on anxiety and depressive symptoms. Iran J Public Health, 42:48-55.

Mohsenabadi H, Zanjani Z, Shabani MJ, Arj A (2018) A randomized clinical trial of the Unified Protocol for Transdiagnostic treatment of 
emotional and gastrointestinal symptoms in patients with irritable bowel syndrome: evaluating efficacy and mechanism of change. J Psychosom Res, 113:8-15.

Mullin A, Dear BF, Karin E, Wootton BM, Staples LG, Johnston L et al. (2015) The UniWellbeing course: A randomised controlled trial of a transdiagnostic internet-delivered cognitive behavioural therapy (CBT) programme for university students with symptoms of anxiety and depression. Internet Interv, 2:128-136.

Newby JM, Mewton L, Andrews G (2017) Transdiagnostic versus disorder-specific internet-delivered cognitive behaviour therapy for anxiety and depression in primary care. J Anxiety Disord, 46:25-34.

Newby JM, McKinnon A, Kuyken W, Gilbody S, Dalgleish T (2015) Systematic review and meta-analysis of transdiagnostic psychological treatments for anxiety and depressive disorders in adulthood. Clin Psychol Rev, 40:91-110.

Norton PJ (2008) An open trial of a transdiagnostic cognitive-behavioral group therapy for anxiety disorder. Behav Ther, 39:242-250.

Norton PJ (2012) A randomized clinical trial of transdiagnostic cognitve-behavioral treatments for anxiety disorder by comparison to relaxation training. Behav Ther, 43:506-517.

Norton PJ, Barrera TL (2012) Transdiagnostic versus diagnosis-specific CBT for anxiety disorders: A preliminary randomized controlled noninferiority trial. Depress Anxiety, 29:874-882.

Norton PJ, Hope DA (2005) Preliminary evaluation of a broad-spectrum cognitive-behavioral group therapy for anxiety. J Behav Ther Exp Psychiatry, 36:79-97.

Norton PJ, Hayes SA, Hope DA (2004) Effects of a transdiagnostic group treatment for anxiety on secondary depression. Depress Anxiety, 20:198-202.

Norton PJ, Barrera TL, Mathew AR, Chamberlain LD, Szafranski DD, Reddy R et al. (2013) Effect of transdiagnostic CBT for anxiety disorders on comorbid diagnoses. Depress Anxiety, 30:168-173.

Owens VA, Hadjistavropoulos HD, Schneider LH, Gullickson KM, Karin E, Titov N et al. (2019) Transdiagnostic, internet-delivered cognitive behavior therapy for depression and anxiety: Exploring impact on health anxiety. Internet Interv, 15:60-66.

Reinholt N, Krogh J (2014) Efficacy of transdiagnostic cognitive behaviour therapy for anxiety disorders: a systematic review and meta-analysis of published outcome studies. Cogn Behav Ther, 43:171-184.

Reinholt N, Aharoni R, Winding C, Rosenberg N, Rosenbaum B, Arnfred S (2017) Transdiagnostic group CBT for anxiety disorders:the unified protocol in mental health services. Cogn Behav Ther, 46:29-43.

Roemer L, Salters K, Raffa SD, Orsillo SM (2005) Fear and avoidance of internal experiences in GAD: Preliminary tests of a conceptual model. Cognit Ther Res, 29:71-88.

Sakiris N, Berle D (2019) A systematic review and meta-analysis of the Unified Protocol as a transdiagnostic emotion regulation based intervention. Clin Psychol Rev, 72:101751.

Steele SJ, Farchione TJ, Cassiello-Robbins C, Ametaj A, Sbi S, Sauer-Zavala S et al. (2018) Efficacy of the Unified Protocol for transdiagnostic treatment of comorbid psychopathology accompanying emotional disorders compared to treatments targeting single disorders. J Psychiatr Res, 104:211-216.

Twohig M, Field C, Armstrong A, Dahl A (2010) Acceptance and mindfulness as mechanisms of change in mindfulness-based interventions for children and adolescents. Assessing mindfulness and acceptance processes in clients: llluminating the theory and practice of change. (Ed RA Baer):225-249. Oakland, New Harbinger Publications.

Titov N, Andrews G, Johnston L, Robinson E, Spence J (2010) Transdiagnostic Internet treatment for anxiety disorders: A randomized controlled trial. Behav Res Ther, 48:890-899.

Titov N, Dear BF, Schwencke G, Andrews G, Johnston L, Craske MG et al. (2011) Transdiagnostic internet treatment for anxiety and depression: a randomised controlled trial. Behav Res Ther, 49:441-452.

Tulbure BT, Rusu A, Sava FA, Sălăgean N, Farchione TJ (2018) A web-based transdiagnostic intervention for affective and mood disorders: randomized controlled trial. JMIR Ment Health, 5:e36.

Vand HDA, Gharraee B, Farid AAA, Bandi MFG, Habibi M (2018) Investigating the effects of the unified protocol on common and specific factors in a comorbid insomniac sample: a single-case experimental design. Iran J Psychiatry Behav Sci, 12(3):e14452.

Varkovitzky RL, Sherrill AM, Reger GM (2018) Effectiveness of the unified protocol for Transdiagnostic treatment of emotional disorders among veterans with posttraumatic stress disorder: a pilot study. Behav Modif, 42:210-230.

Weihs KL, McConnell MH, Wiley JF, Crespi CM, Sauer-Zavala S, Stanton AL (2019) A preventive intervention to modify depression risk targets after breast cancer diagnosis: Design and single-arm pilot study. Psychooncology, 28:880-887.

Wittchen HU, Jacobi F, Rehm J, Gustavsson A, Svensson M, Jönsson B et al. (2011) The size and burden of mental disorders and other 
disorders of the brain in Europe 2010. Eur Neuropsychopharmacol, 21:655-679.

Yazarların Katkıları: Yazarlar çalışmaya önemli bir bilimsel katkı sağladığını ve makalenin hazırlanmasında veya gözden geçirilmesinde yardımc olduklarını kabul etmişlerdir.

Danışman Değerlendirmesi: Dış bağımsız.

Çıkar Çatışması: Yazarlar çıkar çatışması bildirmemiştir.

Finansal Destek: Yazarlar bu çalışma için finansal destek almadıklarını beyan etmişlerdir.

Authors Contributions: The authors attest that they made an important scientific contribution to the study and have assisted with the drafting or revising of the manuscript.

Peer-review: Externally peer-reviewed.

Conflict of Interest: No conflict of interest was declared by the authors.

Financial Disclosure: The authors declared that this study has received no financial support. 